\title{
Imágenes de una identidad portuguesa y la recepción en Portugal del teatro de Lope de Vega
}

\author{
Ângela FERNANDES \\ Centro de Estudos Comparatistas \\ Universidade de Lisboa \\ angfernandes@fl.ul.pt
}

\begin{abstract}
RESUMEN
Este artículo propone la discusión del tema de la "materia portuguesa" en el teatro de Lope de Vega, considerando la funcionalidad de las imágenes de una identidad nacional portuguesa, sea en el contexto peninsular de inicios del siglo XVII o en la recepción contemporánea de la obra de Lope en Portugal. El análisis de la comedia El guante de Doña Blanca, y de su traducción portuguesa de 1972, nos permitirá apreciar el complejo diálogo entre referencias históricas y tópicos poéticos, al mismo tiempo que nos conducirá a la reflexión sobre las posibles lecturas políticas de los referentes culturales de la obra dramática del autor. Aunque no lo parezca de modo evidente, Lope de Vega fue también, en cierto modo, un escritor entre culturas.
\end{abstract}

Palabras clave: Lope de Vega, materia portuguesa, recepción, traducción.

[Recibido, febrero 2012; aprobado, mayo 2012]

\author{
Images of Portuguese identity and the reception of \\ Lope de Vega's theatre in Portugal
}

\begin{abstract}
This article aims at discussing the topic of "Portuguese themes" in Lope de Vega's plays, and it will consider the role of the images of a Portuguese national identity in both the political context of the Iberian Peninsula in the beginning of the $17^{\text {th }}$ century and in the contemporary Portuguese reception of Lope de Vega's theatre. The analysis of the play El guante de Doña Blanca [Doña Blanca's glove] and its 1972 Portuguese translation will show the complex dialogue between historical reference and poetic conventions, and it will lead to a reflection on the possible political reading of cultural referents in Lope's plays. Even if in a less obvious way, Lope de Vega was also, somehow, a writer between cultures.
\end{abstract}

Keywords: Lope de Vega, Portuguese themes, reception, translation. 


\section{Lope de Vega y Portugal}

No hay dudas sobre el conocimiento, la puesta en escena y el comentario crítico del teatro de Lope de Vega en Portugal desde el siglo XVII. La recepción portuguesa de Lope ha seguido una línea evolutiva que permaneció muy cerca de los cambios de gusto y de criterios estéticos que acompañaron la apreciación del teatro clásico español a lo largo de los tiempos (Cf. Rodrigues 1987 y 2005). También en Portugal la revalorización del teatro del Siglo de Oro se inició con los románticos (en especial con Alexandre Herculano ${ }^{1}$ ), pero hay que notar que la preocupación por las raíces de la dramaturgia nacional fue el principal motivo de la atención hacia los autores españoles: para conocer mejor a Gil Vicente, sería necesario conocer también a Lope o a Calderón. Durante el siglo XX, el interés por una presunta dimensión "portuguesa" de la obra de los clásicos españoles aparece, pues, como un aspecto más del esfuerzo de afirmación de una identidad cultural portuguesa a través de los testimonios teatrales más antiguos y notables. En el teatro se comprobaría la permanencia de una idea de identidad nacional distintiva durante los sesenta años de pérdida de la independencia política del reino de Portugal (15801640).

La atención crítica al teatro de Lope de Vega parece confirmar esta tendencia: después de las celebraciones de 1935, diversos críticos han señalado el "lusitanismo" del Fénix ${ }^{2}$ y su conocimiento de Portugal, plasmado en la representación teatral de rasgos de una identidad portuguesa específica, bien reconocible a inicios del siglo XVII. Sin embargo, en el panorama teatral portugués de los siglos XX y XXI, el interés por la dramaturgia de Lope ha sido muy reducido: tenemos noticia de dos puestas en escena de La Dama Boba (en 1953 y 1960), tres de Fuenteovejuna (en 1973, 1983 y 2003, al que se puede añadir una versión musical en 2010), y una producción de La vida y muerte del rey Bamba (en 1989). ${ }^{3}$

La publicación de comedias traducidas es igualmente escasa; hasta el momento, han sido editados solamente dos volúmenes con traducciones portuguesas de comedias de Lope de Vega. En 1967 se publicó, en una importante colección de teatro clásico traducido al portugués, el volumen Teatro de Lope de Vega. Peribáñez e O Comendador de Ocaña, O Cachorro do Hortelão e Fuenteovejuna, reuniendo

\footnotetext{
${ }^{1}$ Véase el panorama histórico del teatro español delineado por Alexandre Herculano en su ensayo de 1839 (Herculano 1986).

${ }^{2}$ Más adelante se comentarán algunos de estos artículos y estudios: Dantas 1936, Raposo 1936, Figueiredo 1941, Viqueira, 1950, Glaser 1954.

${ }^{3} \mathrm{Al}$ final del artículo se encuentra, en forma de Anejo, un cuadro con las traducciones portuguesas editadas y las puestas en escena de obras de Lope de Vega en Portugal desde mediados del siglo XX. Hay registro de la traducción y adaptación radiofónica de cuatro comedias en 1959 (A Boa Guarda, A Dama Tonta, A Fonte das Ovelhas y $O$ Melhor Alcaide, o Rei), y se puede mencionar también la traducción de fragmentos de ocho comedias del autor en la sección "Antologia" (pp. 57-88) del volumen Lope de Vega, publicado en 1972 en una colección de divulgación de clásicos de la "literatura universal".
} 
tres comedias traducidas en prosa por Natália Correia. ${ }^{4}$ Solo cinco años después, en 1972, apareció, en otra relevante colección de clásicos, el volumen Fuenteovejuna, A Luva de Dona Branca, con la traducción versificada de las dos comedias (e incluyendo también el "Arte Nuevo de Hacer Comedias") bajo responsabilidad de António Lopes Ribeiro. ${ }^{5}$

En este panorama, cobran especial interés los criterios de selección de las piezas de Lope de Vega traducidas y/o representadas. El punto de partida para el análisis que aquí presento fue justamente el comentario de Antonio Lopes Ribeiro, el traductor de Fuenteovejuna y El Guante de doña Blanca, sobre sus motivos para elegir estas dos comedias. En un breve prefacio al volumen, explica el traductor que fue tarea muy difícil decidir las obras que podrían dar al lector portugués una idea, aunque resumida, del "genio de Lope de Vega" (Ribeiro 1972: 11). Fuenteovejuna es referida como una opción inevitable porque es "la obra más conocida" del autor; ya la segunda comedia, El guante de Doña Blanca, merece explicación más larga:

A outra [peça], pareceu-nos natural escolhê-la entre aquelas cuja acção se situa em Portugal, ou está ligada à nossa história. Citem-se: La tragedia de Doña Inés de Castro [...], El Guante de Doña Blanca.

A nossa preferência recaiu por fim sobre esta última. Em primeiro lugar, pelo contraste com Fuenteovejuna, pois se trata de uma comédia extremamente alegre e divertida [...]. Depois, por demonstrar o apreço de Lope de Vega pela figura de el-rei D. Dinis, personagem central da peça. Também nos seduziram os saborosos anacronismos, decerto propositados: Lope faz do Rei-Poeta caçador de leões em Ceuta, suserano de Marrocos e da Índia! E ainda pela ironia com que descreve a típica basófia dos Portugueses. (Ribeiro 1972: 11). ${ }^{6}$

Los comentarios de Antonio Lopes Ribeiro repiten algunas de las ideas clave que descubrimos en los artículos y ensayos que discuten el "lusitanismo" de Lope de Vega, y que son relativamente abundantes en el panorama crítico portugués de la primera mitad del siglo XX. En un breve artículo titulado "Lope de Vega em Portugal", Júlio Dantas señalaba que hay "mucho de portugués" en la obra de Lope, quien visitó, "conoció, admiró y cantó" el país vecino (Dantas 1936: 264). Ya Fidelino de Figueiredo, en un estudio más largo y documentado, defiende que diversas comedias de Lope revelan el tratamiento artístico de motivos "lusitanos",

\footnotetext{
${ }^{4}$ Natália Correia (1923-1993) fue una escritora, ensayista e intelectual con importante intervención en la vida cultural y política portuguesa de la segunda mitad del siglo XX.

${ }_{6}^{5}$ António Lopes Ribeiro (1908-1995) fue principalmente conocido como cineasta y crítico de cine.

6 "Nos pareció natural elegir la otra [obra] entre aquellas cuya acción se sitúa en Portugal, o está relacionada con nuestra historia. Por ejemplo, La tragedia de Doña Inés de Castro [...], El Guante de Doña Blanca. Nuestra preferencia recayó al final sobre El Guante de Doña Blanca. En primer lugar, debido al contraste con Fuenteovejuna, pues se trata de una comedia extremadamente alegre y divertida [...]. Luego, porque demuestra la estima de Lope de Vega por la figura del rey D. Dinis, personaje central de la comedia. Nos sedujeron también los sabrosos anacronismos, sin duda deliberados: Lope transforma al rey-poeta en cazador de leones en Ceuta, señor de Marruecos y de la India. Y aún debido a la ironía con la que describe la típica presunción de los portugueses." (Ribeiro 1972: 11). Traducción mía.
} 
concretamente ciertos "matices del espíritu poético, de la galantería cortesana, de la obsesión amorosa, de la arrogancia y del coraje temerario, de la vanidad y del hábil maquiavelismo, que [Lope] tenía como típicamente lusitanos" (Figueiredo 1941: 275 y 279 ; traducción mía).

También José María Viqueira, en complemento al estudio de la comedia El Brasil Restituido, analiza en detalle la presencia del "asunto lusitano" en la obra de Lope y concluye que el autor "miró a Portugal con ojos admirados y lo sintió familiarmente, como algo suyo y entrañable" (Viqueira1950: 199). ${ }^{7}$ En esta línea, hay que mencionar también el ensayo de Edward Glaser sobre "El lusitanismo de Lope de Vega", donde se discute alguna dualidad del autor con respecto a Portugal, pero reconociendo que la creación teatral de Lope "sobresalía en la elaboración de los rasgos nacionales de los portugueses, tanto serios como cómicos" (Glaser 1954: 389).

En un estudio más reciente, José Ares Montes examina la "lusofilia" de los dramaturgos españoles del siglo XVII, y sobre Lope comenta: "No importa que la fidelidad histórica se diluya en la inventiva poética; la historia de Portugal está ahí, vista con admiración y cantada con entusiasmo, así como elogiado en extremo la belleza de las portuguesa y el valor, generosidad y fidelidad de los portugueses." (Ares Montes 1991: 15). También Maria Idalina Resina Rodrigues ha estudiado el tratamiento de las figuras históricas portuguesas en el teatro de los Siglos de Oro, concluyendo que, por regla general, los dramaturgos españoles, y notablemente Lope de Vega, "se mostraban gran defensores de un igual estatuto de hidalguía para portugueses y españoles, siempre a la par en las batallas y en la galantería" (Rodrigues 1999: 315).

En síntesis, las ideas principales de estos comentarios críticos se resumen de modo muy claro: en primer lugar, las comedias de Lope de Vega revelan la "estima" del dramaturgo por las figuras históricas portuguesas (y por Portugal y los portugueses en general); en segundo lugar, el rigor historiográfico es habitualmente sustituido, en las comedias, por anacronismos y por la mezcla de elementos reales e imaginarios, con propósitos artísticos; y por último, el retrato de los portugueses dibujado por Lope conjuga virtudes y defectos nacionales, pero sin agresividad o irreverencia irrespectuosa. Estas premisas articulaban igualmente el argumento de António Lopes Ribeiro, citado arriba; para comprenderlo mejor, deberemos ahora prestar atención a El guante de Doña Blanca, la comedia de Lope de Vega elegida, según afirma el traductor, por motivo de su relación con la historia de Portugal.

\section{El guante de doña Blanca y A Luva de Dona Branca}

El guante de doña Blanca pertenece a la etapa final de la creación de Lope de Vega (Cf. Profeti 2006), y la verdad es que la comedia dice poco de Portugal, o de su historia, o de rasgos nacionales distintivos. Como explica Francisco SánchezCantón, El guante de doña Blanca "es la localización -entiendo que sin fundamen-

\footnotetext{
${ }^{7}$ Véase también la reseña de Jacinto do Prado Coelho al estudio J.M. Viqueira (Coelho 1951) así como el ensayo de Hipólito Raposo (1936).
} 
to alguno- en la corte portuguesa del cuento caballeresco, muy conocido, de la dama que echa, o deja caer, un guante en la jaula de un león." (Sánchez-Cantón 1961: 29). También Maria Grazia Profeti, en la Introducción a su edición crítica de la comedia, señala que El guante de Doña Blanca constituye sobre todo una reelaboración dramatúrgica de la referida leyenda del folclore europeo, muy presente en cancioneros y romanceros españoles, y que Lope habría tomado de Bandello (Profeti 2006: 34). Por consiguiente, será solo un detalle el hecho que la acción tenga lugar en "un mítico Portugal medieval, dominado por la figura de D. Dionís, príncipe culto y refinado" (Profeti 2006: 41).

En la intriga de la comedia, D. Dionís se convierte en rival de Don Juan de Mendoza - el galán de Doña Blanca, y caballero de la corte, por quien ella deja caer el guante (con un escrito dentro) en la jaula del león. El interés de Dionís por Blanca será el principal obstáculo a los amores entre Blanca y Juan, y lo cierto es que tal triángulo de seducción y poder nada tiene de específicamente portugués.

Sin embargo, hay en la comedia algunos momentos donde parece emerger una idea de Portugal, y de una cierta identidad portuguesa. Por ejemplo, las características de valentía y de sensibilidad son mencionadas explícitamente por el criado Brito, sea en tono serio, sea en clave cómica, como rasgos portugueses (Acto I):

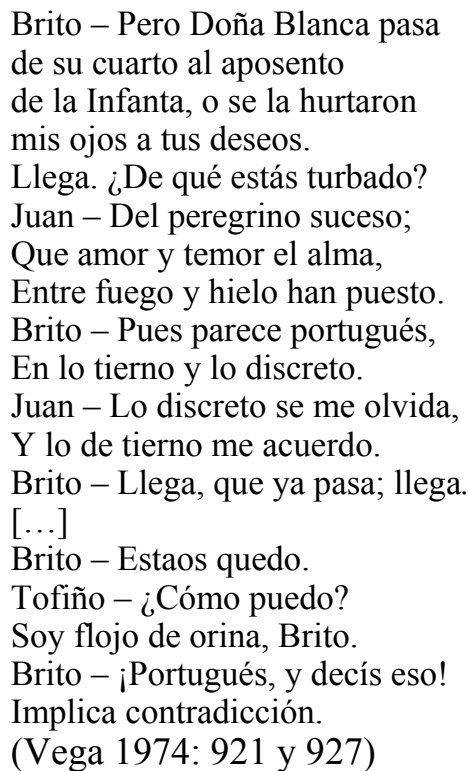

Al mismo tiempo, son mencionadas algunas informaciones sobre la realidad histórica portuguesa, aunque mezclando el Portugal del siglo XIII, de la época del Rey-poeta D. Dionís (1261-1325) y de su boda con doña Isabel de Aragón, en 1282 , con la realidad portuguesa del siglo XVI, y los dominios imperiales en África y en las Indias orientales. En el acto II, el Rey D. Dionís advierte a Juan: 
Rey - No os quiero tan fatigado, pues Castilla no embaraza con guerra nuestro Consejo, y Aragón de espacio trata la venida de Isabel; el África feudataria reconoce el señorío; la India las naves carga de oro y blancas margaritas, dos hijos del sol y del alba. (Lope 1974: 931)

Es preciso recordar que en la época de creación de El guante de Doña Blanca, es decir, en los últimos años de vida de Lope de Vega (c.1625-35), la nación portuguesa continuaba incorporada al imperio español, así que, en el impreciso tiempo histórico de la comedia, los detalles de la historia ilustre de Portugal se funden, sin gran sorpresa, con las virtudes del universo hispánico. El contexto de unión política y de contacto cultural tendrá, pues, que ser considerado en la lectura de tales referencias. Aunque los motivos poéticos y dramatúrgicos sean de indudable relevancia en la composición de las comedias de Lope, hay que reconocer que aquí las alusiones a Lisboa, a Portugal, a los portugueses, o al imperio, no se pueden leer solo, como sugiere Edward Glaser, como resultado de "razones puramente artísticas, como la necesidad de variación o la de proporcionar cierto desahogo cómico" (Glaser 1954: 388). Algunos de los estudios, ya mencionados, sobre los elementos portugueses en la obra de Lope de Vega, indican justamente la ambigua mezcla de motivaciones poéticas y políticas en el tratamiento de la "materia portuguesa". José Ares Montes propone, incluso, una doble explicación política para lo que designa como la "insistente predilección" de los dramaturgos españoles del siglo XVII por los temas portugueses:

Por un lado, podría descubrirse un intento de aquietar los ánimos portugueses, cada vez más descontentos con la política desarrollada en Portugal por las autoridades españolas y sus colaboradores lusitanos, mediante la divulgación de su pasado histórico, el elogio de reyes y nobles y la exaltación de las virtudes del pueblo portugués. Por otro lado, y esto cara al público español, la afirmación imperialista de que las glorias portuguesas lo eran también españolas. (Ares Montes 1991: 20).

La situación política de las naciones ibéricas a principios del siglo XVII sería propicia al énfasis en identidades próximas y convergentes. Algo de esta visión política de la época resonará en El guante de doña Blanca, pero la intriga amorosa y los tópicos de la leyenda folclórica atenúan cualquier implicación más obvia. Lope de Vega y su comedia se sitúan, así, entre la cultura literaria y dramatúrgica del momento (en la que se incluye el juego con los lugares comunes sobre las identidades peninsulares) y el contexto político que favorece la mezcla de identidades históricas y culturales. 
Si El guante de doña Blanca presenta una imagen difusa, aunque cordial, de Portugal, ya la traducción portuguesa de la comedia propone una visión más clara. El análisis de A Luva de Dona Branca revela cómo el traductor Antonio Lopes Ribeiro se esforzó por "corregir" diversos detalles del texto, llevando su lector a presumir una más nítida presencia de la "materia portuguesa", o de la "estima" de Lope por el rey D. Dinis y por Portugal. La traducción procura asegurar el reconocimiento de una distinta identidad portuguesa en la comedia de Lope de Vega: lo que se dice "español" en la comedia pasa a menudo a ser "portugués" en la traducción de António Lopes Ribeiro.

Consideremos, por ejemplo, el cambio introducido en un comentario sobre el rey poeta:

Leonor $-(\ldots)$ Que es, Blanca, si no lo sabes,

El rey Dionís el primero

que en España en lengua propia

hizo versos.

(Vega 1974: 930; Acto II)

D. Leonor - Porém, toda a gente diz

que, de longe, o principal

poeta de Portugal

é o próprio Rei Dom Dinis.

(Vega 1972: 125)

Los cambios "lusitanos" del traductor Antonio Lopes Ribeiro son muy evidentes. También en el acto III, la afirmación del Rey "Porque es blasón español/saber honrar las mujeres" (Vega 1974: 947) deviene "Que é brasão dos Portugueses / saber honrar as mulheres" (Vega 1972: 173). Pero la ocasión donde el traductor manipula de manera más evidente el texto de la comedia ocurre casi al final, cuando el rey declara a Blanca su amor y admite tener celos de D. Juan Mendoza. D. Blanca le persuade de su mayor valor, y así consigue que don Dionís desista de su empresa seductora, pero el diálogo es revelador de la actitud potencialmente violenta del monarca. Para preservar la imagen de D. Dinis, y la idea de la "estima" de Lope por el rey portugués ${ }^{9}$, el traductor omite la intervención más violenta:

Rey - ¿Que soy mejor caballero

En todas acciones yo?

Blanca - Sí, señor.

\footnotetext{
${ }^{8}$ La traducción de la comedia, publicada en 1972 en la colección "Livros RTP", no se destinaba a la puesta en escena, sino a la divulgación literaria. Las consideraciones sobre la complejidad del trabajo de traducción del teatro de Lope (e.g. Johnston 2008) solo en parte son pertinentes aquí, ya que los condicionamientos escénicos no se aplican a la traducción de A. L. Ribeiro.

${ }^{9}$ En el prefacio a la traducción, A. L. Ribeiro afirma que, pese a alguna ironía, Lope no "disminuye en nada la figura del soberano, cuya propensión amorosa y espíritu superior destaca a menudo" (Ribeiro 1972: 11).
} 
Rey - ¿Y que si quiero, puedo a mi fuerza rendirte?

Blanca - Sí, señor.

Rey - Pues si yo excedo

En todo al galán Mendoza, ¿Qué vencimiento, que reino Como ser rey de mi mismo? Blanca, adiós; adiós, deseos. Blanca se da por vencida, $\mathrm{Y}$ yo me doy por contento. (Vega 1974: 941; Acto III)

El-Rei - Que sou melhor cavaleiro em todas as coisas?

D. Blanca - Sim, Senhor. El-Rey - Pois se em tudo excedo o teu galã João Mendonça, haverá maior vencimento do que ser rei de mim mesmo? Adeus, Branca; adeus, desejos. Branca se dá por vencida, E eu dou-me por contente.

(Vega 1972: 157)

En síntesis, A Luva de Dona Branca, texto traducido en el siglo XX, es claramente más benévolo con la figura del rey medieval y más alabador del pueblo portugués que El guante de doña Blanca, comedia de Lope de Vega escrita en el siglo XVII. El traductor procuró acentuar una idea de "lusitanismo" casi ideológico, idea que podría ser deseada en el Portugal de los últimos años de la dictadura del Estado Novo, pero que, en rigor, no se encuentra en la comedia de Lope. En el cruce de tópicos literarios y elementos histórico-políticos, El guante de doña Blanca propone la compleja y heterogénea imagen de una identidad portuguesa basada en la figura paradójica de un rey medieval galanteador, que escribe sonetos y es señor de África y de India.

Así se comprende mejor cómo la noción de una identidad nacional se basa en imágenes que, ante de todo, se deben entender como elementos de un juego a la vez social y artístico, que cambia en el tiempo, y en el que participan autores, traductores, lectores, espectadores y críticos. Más importante que determinar si Lope de Vega "estimaba" Portugal, será mostrar cómo una comedia como El guante de doña Blanca sobrevive gracias a la sutileza del juego de identidades que sugiere.

\section{Referencias bibliográficas}

ARES MONTES, José (1991): "Portugal en el teatro español del siglo XVII", Revista de Filología Románica 8: 11-29. 
COELHO, Jacinto do Prado (1951): "Recensão de J. M. Viqueira Barreiro, El lusitanismo de Lope de Vega", Revista da Faculdade de Letras, Tomo XVII, $2^{\mathrm{a}}$ Série, $\mathrm{n}^{\circ}$ 1-3: 242-243.

DANTAS, Júlio (1936): "Lopo de Vega em Portugal", Viagens em Espanha. Lisboa: Livraria Bertrand. 261-268.

FIGUEIREDO, Fidelino de (1941): "Lope de Vega: alguns elementos portugueses na sua obra", Últimas Aventuras. Rio de Janeiro: Empresa A Noite Editora. 255-325.

GLASER, Edward (1954): "El lusitanismo de Lope de Vega", Boletín de la Real Academia Española, Año XLIII, Tomo XXXIV, Cuaderno CXLIII, Septiembre-Diciembre 1954: 387-412.

HERCULANO, Alexandre (1986): "História do teatro moderno - teatro espanhol" (1839), Opúsculos V, ed. Jorge Custódio \& José Manuel Garcia. Lisboa: Presença. 71-82.

JOHNSTON, David (2008): "Lope in Translation: Opening the Closed Book", $A$ Companion to Lope de Vega, ed. Alexander Samson \& Jonathan Thacker. Woodbridge: Tamesis. 300-313.

Lope de Vega, trad. Leopoldo de Araújo \& Ricardo Alberty. Lisboa: Editorial Verbo (Col. Gigantes da Literatura Universal, $\left.\mathrm{n}^{\circ} 10\right), 1972$.

PROFETI, Maria Grazia (2006): "Introduzione", Lope de VEGA, Comedias della "Vega del Parnaso" I. El guante de doña Blanca, ed. Maria Grazia Profeti, Firenze, Alinea Editrice. 7-46.

RAPOSO, Hipólito (1936): "O sentimento português em Lope de Vega", Aula Régia. Porto: Livraria Civilização. 299-367.

RIBEIRO, António Lopes (1972): "Prefácio", Lope de VEGA, Fuenteovejuna, A Luva de Dona Branca, trad. António Lopes Ribeiro. Lisboa: Editorial Verbo (Col. Biblioteca Básica Verbo - Livros RTP, n 81). 7-12.

RODRIGUES, Maria Idalina Resina (1987): "Fortuna e Infortúnios de Lope de Vega em Portugal (1580-1870)", Estudos Ibéricos. Da Cultura à Literatura. Pontos de Encontro. Séculos XIII a XVII. Lisboa: Instituto de Cultura e Língua Portuguesa. 208-249.

- (1999): "Virtudes, pecados e confusões pouco inocentes: D. João II no teatro de Lope de Vega", De Gil Vicente a Lope de Vega: Vozes Cruzadas no Teatro Ibérico. Lisboa: Editorial Teorema. 297-320.

- (2005): "Lope de Vega", Biblos. Enciclopédia Verbo das Literaturas de Língua Portuguesa. Lisboa - São Paulo: Editorial Verbo, vol. V, col. 652-658.

SÁNCHEZ-CANTON, Francisco J. (1961): "Personajes y sucesos de la Edad Media portuguesa en el teatro español", Las Ciencias, $\mathrm{n}^{\circ}$ 26: 26-35.

VEGA, Lope de (1967): Teatro de Lope de Vega. Peribáñez e O Comendador de Ocaña, O Cachorro do Hortelão e Fuenteovejuna, trad. Natália Correia. Porto Barcelos: Livraria Civilização Editora - Companhia Editora do Minho (Col. Civilização Teatro). 
- (1972): Fuenteovejuna, A Luva de Dona Branca, trad. António Lopes Ribeiro. Lisboa: Editorial Verbo (Col. Biblioteca Básica Verbo - Livros RTP, ${ }^{\circ}$ 81). [incluye «Arte Nova de Fazer Comédias neste Tempo»]

- (1974): "El guante de Doña Blanca", in Obras Escogidas, Tomo III, ed. Federico Carlos Sainz de Robles. Madrid: Aguilar. 919-949.

VIQUEIRA BARREIRO, José Maria (1950): "El lusitanismo de Lope de Veja", El lusitanismo de Lope de Veja y su comedia "El Brasil restituído». Estúdio biobibliográfico, notas y comentários. Coimbra: Coimbra Editora Lda. 153-199. [separata de Brasília, vol. V, Instituto de Estudos Brasileiros da Faculdade de Letras da Universidade de Coimbra]

\section{Anexo}

Traducción, edición y puesta en escena de comedias de Lope de Vega en Portugal (1950-2011)

\begin{tabular}{|c|c|c|c|c|}
\hline Comedia traducida & Fecha & Traductor & Edición & Puesta en Escena \\
\hline $\begin{array}{l}\text { O Cachorro do } \\
\text { Hortelão }\end{array}$ & 1967 & Natália Correia & $\begin{array}{l}\text { Porto - Barcelos, Livraria } \\
\text { Civilização Editora - Companhia } \\
\text { Editora do Minho (Col. } \\
\text { Civilização Teatro). } \\
\text { [Edición conjunta: Peribáñez e O } \\
\text { Comendador de Ocaña, } O \\
\text { Cachorro do Hortelão, } \\
\text { Fuenteovejuna] }\end{array}$ & \\
\hline A Dama Tonta & 1960 & Ricardo Alberty & & $\begin{array}{l}\text { Grupo de Teatro } \\
\text { Experimental - } \\
\text { Teatro da Rua da } \\
\text { Fé, Lisboa. }\end{array}$ \\
\hline Fuenteovejuna & 1962 & Salette Tavares & & $\begin{array}{l}\text { TEUC - Teatro } \\
\text { dos Estudantes da } \\
\text { Universidade de } \\
\text { Coimbra } \\
\text { [espectáculo } \\
\text { proibido por la } \\
\text { censura]. }\end{array}$ \\
\hline Fuenteovejuna & 1967 & Natália Correia & $\begin{array}{l}\text { Porto - Barcelos, Livraria } \\
\text { Civilização Editora - Companhia } \\
\text { Editora do Minho (Col. } \\
\text { Civilização Teatro). } \\
\text { [Edición conjunta: Peribáñez e O } \\
\text { Comendador de Ocaña, O } \\
\text { Cachorro do Hortelão, } \\
\text { Fuenteovejuna] }\end{array}$ & $\begin{array}{l}\text {-Teatro } \\
\text { Experimental de } \\
\text { Cascais, } 1973 . \\
\text {-TELA - Teatro } \\
\text { Experimental de } \\
\text { Leiria, 1983. } \\
\text { - CENDREV - } \\
\text { Centro Dramático }\end{array}$ \\
\hline
\end{tabular}




\begin{tabular}{|c|c|c|c|c|}
\hline & & & & $\begin{array}{l}\text { de Évora. } 2003 . \\
\text { - Teatro Villaret: } \\
\text { O que faz falta- } \\
\text { Musical, } 2010 .\end{array}$ \\
\hline Fuenteovejuna & 1972 & $\begin{array}{l}\text { António Lopes } \\
\text { Ribeiro }\end{array}$ & $\begin{array}{l}\text { Lisboa, Editorial Verbo (Col. } \\
\text { Biblioteca Básica Verbo - Livros } \\
\text { RTP, n }{ }^{\circ} 81 \text { ). } \\
\text { [Edición conjunta: Fuenteovejuna, } \\
\text { A Luva de dona Branca] }\end{array}$ & \\
\hline A Luva de Dona Branca & 1972 & $\begin{array}{l}\text { António Lopes } \\
\text { Ribeiro }\end{array}$ & $\begin{array}{l}\text { Lisboa, Editorial Verbo (Col. } \\
\text { Biblioteca Básica Verbo - Livros } \\
\text { RTP, } \mathrm{n}^{\circ} \text { 81). } \\
\text { [Edición conjunta: Fuenteovejuna, } \\
\text { A Luva de dona Branca] }\end{array}$ & \\
\hline A Menina Tonta & 1953 & $\begin{array}{l}\text { Leopoldo de } \\
\text { Araújo }\end{array}$ & & \begin{tabular}{l}
\multicolumn{1}{c}{ Companhia } \\
Rey Colaço - \\
Robles Monteiro.
\end{tabular} \\
\hline $\begin{array}{l}\text { Peribáñez e o } \\
\text { Comendador de Ocaña }\end{array}$ & 1967 & Natália Correia & $\begin{array}{l}\text { Porto - Barcelos, Livraria } \\
\text { Civilização Editora - Companhia } \\
\text { Editora do Minho (Col. } \\
\text { Civilização Teatro). } \\
\text { [Edición conjunta: Peribáñez e O } \\
\text { Comendador de Ocaña, } O \\
\text { Cachorro do Hortelão, } \\
\text { Fuenteovejuna] }\end{array}$ & \\
\hline Vida e Morte de Bamba & 1989 & $\begin{array}{l}\text { Luiza Neto } \\
\text { Jorge \& Manuel } \\
\text { João Gomes }\end{array}$ & & $\begin{array}{l}\text { Teatro da } \\
\text { Cornucópia. }\end{array}$ \\
\hline
\end{tabular}

\section{Fuentes principales:}

CETbase - Teatro em Portugal, Centro de Estudos de Teatro da Universidade de Lisboa: http://www.fl.ul.pt/CETbase (último acceso: 12.01.2012).

TETRABASE - Teatro e Tradução, Centro de Estudos Comparatistas da Faculdade de Letras da Universidade de Lisboa: http://tetra.fl.ul.pt/base (último acceso: 12.01.2012). 